\title{
Students' satisfaction with the quality of educational services
}

\author{
Svetlana Yurievna Mitrofanova ${ }^{1 *}$, Lyudmila Vladimirovna Vandysheva $^{2}$, and Anna \\ Aleksandrovna Pustarnakova ${ }^{1}$ \\ ${ }^{1}$ Samara National Research University after S. P. Korolev, Department of Sociology and Cultural \\ Studies, Samara, Russia \\ ${ }^{2}$ Samara National Research University after S. P. Korolev, Department of Theory and Technology of \\ Social Work, Samara, Russia
}

\begin{abstract}
The article raises the problem of the level of satisfaction with educational services among the students of agricultural training areas of secondary vocational education institutions of the Samara region. The study goal is addressed through several objectives including identifying the level of students' satisfaction with the quality of education, their attitude towards industry internship, the level of satisfaction with the quality of material and technical support, and the presence or absence of the desire for employment in the chosen direction of training. The research method deployed in the study is surveying $(\mathrm{N}=123)$. The study reveals that most respondents $(73.7 \%)$ are completely or rather satisfied with the quality of education. The calculations indicate that most respondents have a positive or rather positive attitude towards industry internship (70.8\%). $89.4 \%$ of respondents are completely or rather satisfied with the quality of material and technical support. $84.5 \%$ of the respondents are completely or rather satisfied with the quality of educational services while $9.6 \%$ found it difficult to answer and $5.7 \%$ express dissatisfaction with the quality of educational services to varying degrees. Considering individual educational institutions, the results by the indicator are as follows: the Bezenchuk Agrarian Technical College $-80.8 \%$, the Kinel State Technical College $-91.1 \%$. Due to the lack of data on secondary educational institutions, the obtained results are compared to similar studies conducted in Russian higher education institutions. As a result, the authors report a paradoxical situation consisting in the fact that the students are satisfied with educational services but not all of them plan to continue working in the chosen direction of professional training. Appropriate recommendations are provided for the management of educational institutions in accordance with the obtained results.
\end{abstract}

Keywords: level of satisfaction, quality of education, attitude to industry internship, satisfaction with the quality of material and technical support.

\footnotetext{
*Corresponding author: mit_s@mail.ru
} 


\section{Introduction}

In modern Russian society, the state pays considerable attention to the educational programs whose graduates' potential employment constructs the real sector of the economy. At the same time, a paradoxical situation is observed in several areas of training in secondary vocational education due to the fact that although the state provides the opportunity to obtain secondary vocational education for free to provide the labor market with personnel for this industry, the country's agriculture is experiencing a shortage of personnel, primarily in bluecollar occupations.

The relevance of the study is shaped by the following aspects. Firstly, the existing regulatory framework requires an independent assessment of the quality of education. Secondly, a shortage of personnel is observed in working professions in the field of agriculture. Thirdly, there appears to be a need for sociological and pedagogical understanding of the processes taking place in secondary vocational education institutions.

Meanwhile, we have to highlight that compared to students in secondary vocational institutions, various aspects of life of university students are substantially represented in sociological and pedagogical literature including the aspects of formation of social activity and students' involvement in volunteering [1], the development of students' educational [2] and professional identity [3], the structure of their values [4], students' social adaptation [5], adaptation of first-year students [6] and the factors affecting the process of adaptation [7], adaptation of foreign students at universities [8, 9], adaptation of students in large universities, and the difficulties faced by students in the process of learning and communication at the university [10]. Of special interest to us are the studies of I.A. Zelenev [11] and G.N. Gaidukova [12].

The goal of the study is to determine the level of satisfaction with the quality of educational services among students in agricultural training areas. The study was conducted in March and April of 2020. The object of the study is students of agricultural training areas in 15 secondary vocational education institutions of the Samara region. The statistical population of the study is 5,428 people. Initially, the sample included 385 students. However, due to the onset of the COVID-19 pandemic and the transition to distance learning, we gained access to two educational institutions - the State Budgetary Vocational Education Institution "Bezenchuk Agrarian Technical College" and the State Budgetary Vocational Educational Institution of the Samara Region "Kinel State Technical College", as a result of which the volumes of the general and sample populations were adjusted. The general population comprises 1129 people and the sample population includes 123 students ${ }^{\dagger}$. The stratified selection was used for each institution at the first stage of the study and the second stage deployed mechanical selection. The study goal is addressed through several objectives including identifying the level of students' satisfaction with the quality of education, their attitude towards industry internship, the level of satisfaction with the quality of material and technical support, and the presence or absence of the desire for employment in the chosen direction of training. The listed objectives are set due to the structure of the educational service in accordance with the Federal State Educational Standards of the Russian Federation.

\section{Methods}

A survey for the study was developed with consideration of the study objectives. The indicators allowing to assess the level of satisfaction with the quality of educational services

\footnotetext{
$\dagger$ Field work on data collection and data processing was carried out by V.A. Grashin, a master's student at Samara University in sociology under the supervision of S.Iu. Mitrofanova. The master's student realized the idea of his supervisor.
} 
that are considered to be the most significant are satisfaction with the quality of education, students' attitude to industrial practice. and satisfaction with material and technical support. Each of these indicators in itself is a compound one. Satisfaction with material and technical support is examined through satisfaction with its individual components, satisfaction with the quality of training - through an interest in learning, academic performance, and assessment of the usefulness of the obtained knowledge. Attitudes towards industrial practice are assessed through a specially developed Likert scale.

\section{Results}

The assessment of satisfaction with the quality of education as the main indicator is obtained through the values of its individual components: interest in learning, academic performance, and assessment of the usefulness of the obtained knowledge. The answers of respondents containing contradictions were excluded from data processing, thus, the total number of respondents taken as $100 \%$ amounts to 114 people (Figure 1).

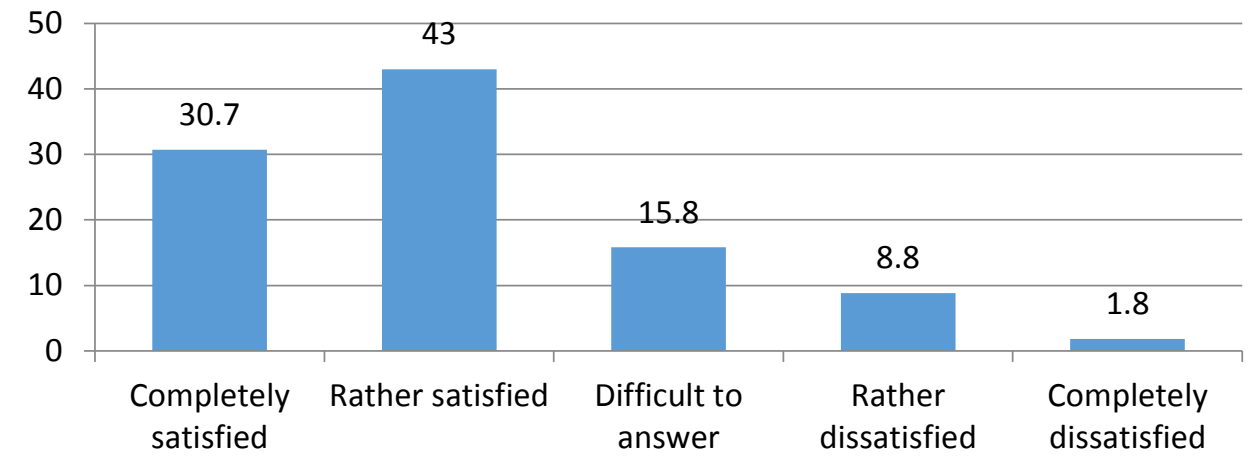

Fig. 1. Distribution of the respondents' answers by the assessed indicator of satisfaction with the quality of education (in \% of the number of respondents)

The majority of the sample of respondents, $73.7 \%$, is completely or rather satisfied with the quality of education, specifically, $61.5 \%$ of the surveyed students from the SBVEI "Bezenchuk Agrarian Technical College" and $80.0 \%$ of students from the SBVEI SR "Kinel State Technical College". The presence of significant differences between the institutions in this aspect is evidenced by the data on the index of satisfaction with the quality of education: 0.34 in the Bezenchuk Agrarian Technical College and 0.56 in the Kinel State Technical College.

One of the major indicators of satisfaction with the quality of educational services used in the study is the respondents' attitude towards industry internships. To measure it, 4 positive and 4 negative judgments were developed according to the criteria characterizing the most important aspects of industry internship:

1. Industry internship as an opportunity to consolidate the knowledge gained during training:

"+" Internship allows me to get the necessary experience to consolidate theoretical knowledge,

"-." Internship is not related to the process of learning and consolidation of knowledge;

2. Internship as an opportunity to develop practical skills:

"+" Success in the profession can only be achieved through practical skills;

"." Practical skills in the profession forms in the process of work and do not depend on industry internship; 
3. Internship as one of the stages of obtaining a diploma in education:

"+" I need the internship to get a diploma;

"-" The internship is a mere formality and will not affect the diploma;

4. Internship as an opportunity for future employment in the specialty:

"+" The internship allows one to make professional acquaintances and get a job in one's specialty after training;

"--" Employment in the specialty and the internship are different things.

A positive attitude towards industry internship is characterized by agreement with the "positive" judgments and disagreement with the "negative" ones while a negative attitude is the opposite. Calculations show that the majority of respondents, $70.8 \%$, have a rather positive and affirmative attitude towards industry internships. A neutral attitude to the internship is demonstrated by $24.4 \%$ of the respondents and $4 \%$ of the studied students show a negative or rather negative attitude to the internship. Considering the studied institutions individually, a positive and rather positive attitude to internships is demonstrated by $79.5 \%$ of students from the Bezenchuk Agrarian Technical College and 57.8\% of the respondents from the Kinel State Technical College.

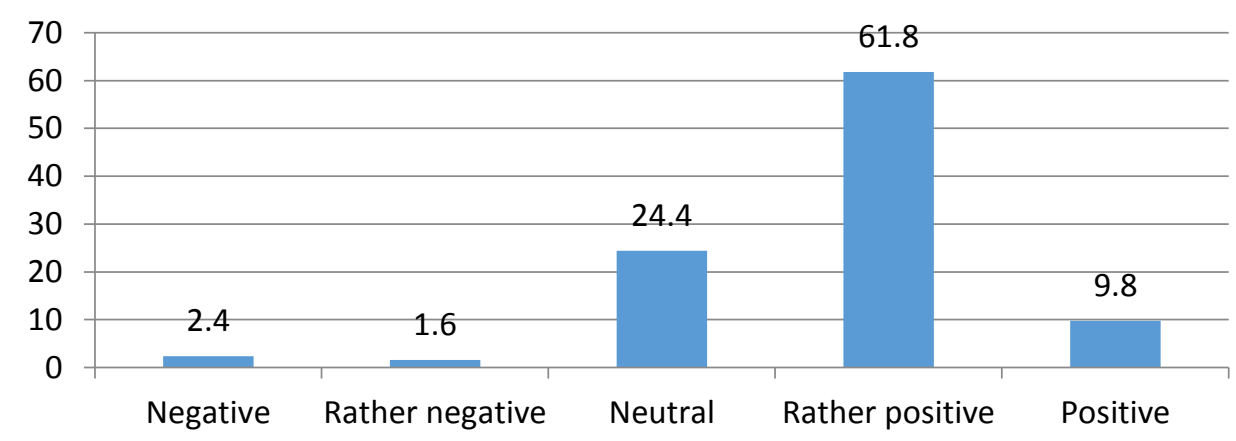

Fig. 2. Distribution of respondents' answers by the assessed indicator of students' attitude towards industry internship (in \% of the number of respondents)

The assessment of satisfaction with the quality of material and technical support is obtained through combining the values of the individual indicators of satisfaction with the state of premises, computer equipment, and the industrial base. $89.4 \%$ of the respondents are completely satisfied and rather satisfied with this aspect while $2.4 \%$ found the question difficult to answer. $8.1 \%$ of the respondents are completely dissatisfied or rather dissatisfied with the quality of material and technical support (Figure 3). 


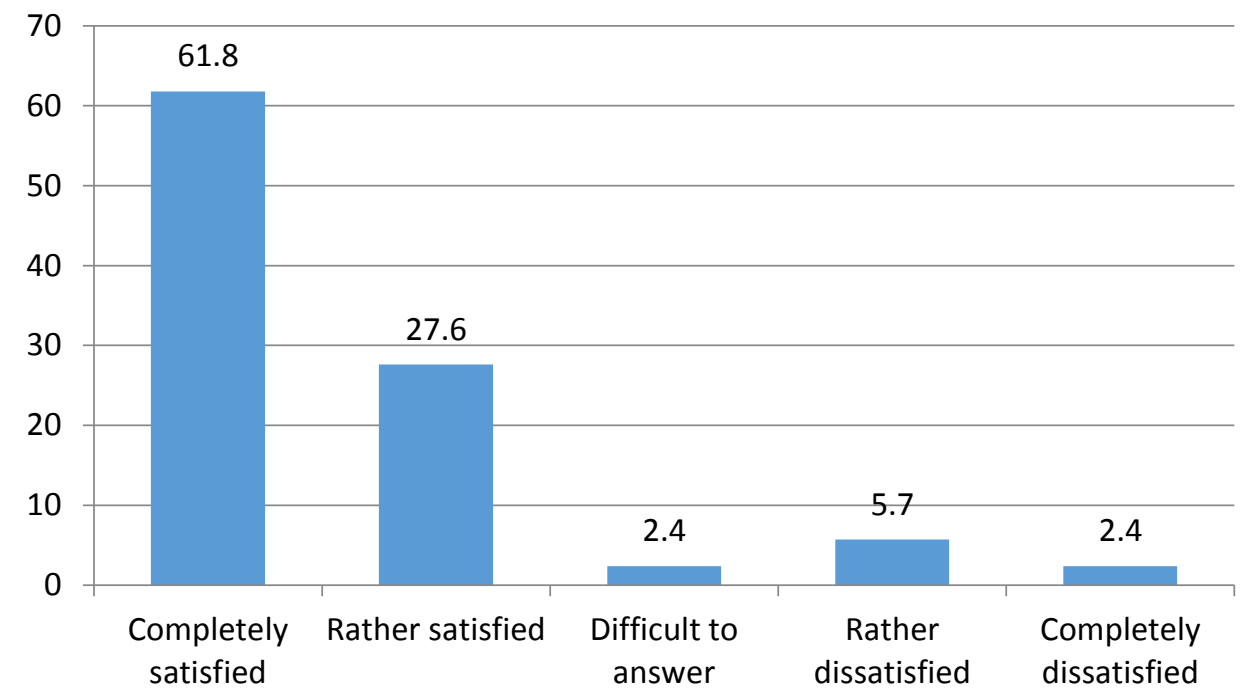

Fig. 3. Distribution of the respondents' answers by the assessed indicator of satisfaction with the quality of material and technical support (in \% of the number of respondents)

Thus, satisfaction with the quality of educational services is determined based on combining the respondents' answers regarding the level of satisfaction with the quality of education, their attitude towards industry internship, and the level of satisfaction with the quality of material and technical support.

Table 1. Satisfaction with the quality of educational services in the total sample and by the educational institutions of the Samara region (in \% of the number of respondents)

\begin{tabular}{|c|c|c|c|}
\hline $\begin{array}{l}\text { Satisfaction with the } \\
\text { quality of education }\end{array}$ & $\begin{array}{l}\text { Total sample, } \\
\text { \% }\end{array}$ & $\begin{array}{l}\text { Bezenchuk Agrarian } \\
\text { College, \% }\end{array}$ & $\begin{array}{l}\text { Kinel State Technical } \\
\text { College, \% }\end{array}$ \\
\hline Completely satisfied & 46.3 & 44.9 & 48.9 \\
\hline Rather satisfied & 38.2 & 35.9 & 42.2 \\
\hline Difficult to answer & 9.6 & 12.8 & 4.4 \\
\hline Rather dissatisfied & 4.1 & 5.1 & 2.2 \\
\hline $\begin{array}{l}\text { Completely } \\
\text { dissatisfied }\end{array}$ & 1.6 & 1.3 & 2.2 \\
\hline Total & 100 & 100 & 100 \\
\hline $\begin{array}{l}\text { Index of satisfaction } \\
\text { with quality of } \\
\text { educational services }\end{array}$ & 0.62 & 0.58 & 0.67 \\
\hline
\end{tabular}

Table 1 shows that $84.5 \%$ of the respondents are completely satisfied with the quality of educational services while $9.6 \%$ found the questions difficult to answer and $5.7 \%$ are to varying degrees dissatisfied with the quality of educational services. Considering individual educational institutions, the results on the indicator are as follows: the Bezenchuk Agrarian Technical College $-80.8 \%$, the Kinel State Technical College $-91.1 \%$. The degree of satisfaction with educational services in the study conducted by E.V. Mezentseva at a university amounts to $84 \%$ [13].

The analysis of results on the respondents' desire for employment in their specialty shows that $56.1 \%$ of the students are going to work in their specialty (the Bezenchuk Agrarian Technical College $-69.2 \%$, the Kinel State Technical College - 33.3\%), $19.5 \%$ are undecided (the Bezenchuk Agrarian Technical College - 15.4\%, the Kinel State Technical College $-26.7 \%$ ), and almost $24.4 \%$ of the respondents are not going to work in their 
specialty (Figure 4). The increased concern is raised by the fact that the students of the Kinel State Technical College report the lowest interest in working in their specialty.

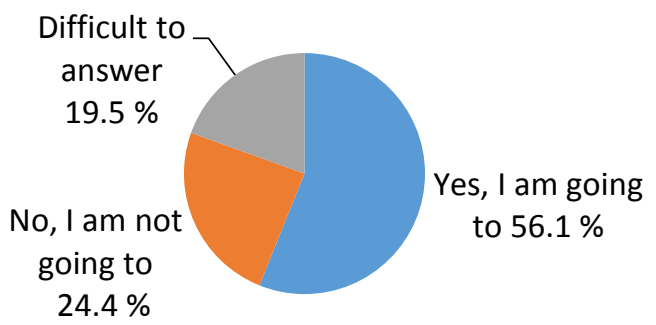

Fig. 4. Distribution of respondents on the question of employment in their specialty (in \% of the total number of respondents)

\section{Discussion and conclusion}

Compared to the results of the study conducted by I.A. Zelenev where the level of satisfaction with the quality of education amounts to $64.1 \%$ [11] and the study conducted by G.N. Gaidukova where the level of satisfaction with the quality of education among university students is $74.62 \%$ [12], the results of the present study on satisfaction with the quality of education in the Bezenchuk Agrarian Technical College (61.5\%) raises some concerns as it is much below the level revealed these studies.

Even though the sample generally is dominated by students who are satisfied with the quality of educational services, of some concern is the situation in the Bezenchuk Agrarian Technical College the satisfaction of respondents in which is lower compared to the study by E.V. Mezentsova.

As a result, we deal with a paradoxical situation shaped by the fact that although students are satisfied with the provided educational services, not all of them plan to continue working in their specialty. Given the obtained results, we believe that job search activities on the part of the management of educational institutions, as well as students' participation in activities related to increasing the prestige of their profession, could affect the positive decision of graduates regarding the choice of future employment in the chosen direction of vocational training. We consider it possible to recommend the heads of other secondary vocational education institutions to conduct a similar study to assess the situation regarding student satisfaction with the quality of educational services in their institutions.

\section{References}

1. L.V. Vandysheva, Yaroslavl Pedagogical Bulletin, 3(114), 75-80 (2020)

2. M.A. Forgey, A. Ortega-Williams, Advances in Social Work, 17(1), 59-77 (2016)

3. J. Lee, P.M. Hernandez, I. Marshal, Journal of Evidence-Based Social Work, 16(6), 669-686 (2019)

4. V.G. Moore, Listant Education: A System View (Wadsworth Publishing, MapQuest,1996)

5. A. B. Smoyer, K. O’Brien, E. Rodriguez-Keyes, International Social Work, 63(5), 651-654 (2020). https://doi.org/10.1177/0020872820940021

6. A.A. Pustarnakova, L.V. Vandysheva, S.Yu. Mitrofanova, Social Adaptation of Foreign Students in Higher Educational Institutions (Case of Samara University), in 
Proceedings of the Ecological-Socio-Economic Systems: Models of Competition and Cooperation (ESES 2019), 185-188 (2020).

7. A. I. Clinciu, Procedia - Social and Behavioral Sciences, 78, 718-722 (2013)

8. P. Mudhovozi, Journal of Social Sciences, 33, 251-259 (2012)

9. V. V. Ryabov, V.M. Ananishnev, A.V. Ivanov, A.V. Tkachenko, V. Merkushin, G.A. Akhtyan, EurAsian Journal of BioSciences Eurasia J Biosci, 13, 2343-2348 (2019)

10. M.J. Westwood, M. Barker, International Journal of Intercultural Relations, 14(2), 251-263 (1990)

11. I.A. Zelenev, Higher Education in Russia, 11, 99-105 (2012)

12. G.N. Gaidukova, Higher Education in Russia, 11, 105-111 (2012)

13. E.V. Mezentseva, L.A. Koroliuk, N.E. Astankova, Humanities, Social-economic and Social Sciences, 5, 38-41 (2015) 